University of Nebraska - Lincoln

DigitalCommons@University of Nebraska - Lincoln

USDA National Wildlife Research Center - Staff Publications
U.S. Department of Agriculture: Animal and Plant Health Inspection Service

2011

\title{
Coyote Capture Vulnerability Relative to Space Use and Trap Density
}

Ryan R. Wilson

Utah State University, ryan.wilson@aggiemail.usu.edu

Julie K. Young

Institute for Wildlife Studies, julie.k.young@aphis.usda.gov

John Shivik

USDA Wildlife Services NWRC, Logan UT, john.shivik@aphis.usda.gov

Follow this and additional works at: https://digitalcommons.unl.edu/icwdm_usdanwrc

Wilson, Ryan R.; Young, Julie K.; and Shivik, John, "Coyote Capture Vulnerability Relative to Space Use and Trap Density" (2011). USDA National Wildlife Research Center - Staff Publications. 1380.

https://digitalcommons.unl.edu/icwdm_usdanwrc/1380

This Article is brought to you for free and open access by the U.S. Department of Agriculture: Animal and Plant Health Inspection Service at DigitalCommons@University of Nebraska - Lincoln. It has been accepted for inclusion in USDA National Wildlife Research Center - Staff Publications by an authorized administrator of DigitalCommons@University of Nebraska - Lincoln. 


\title{
Coyote Capture Vulnerability Relative to Space Use and Trap Density
}

\author{
RYAN R. WILSON, ${ }^{\mathbf{1 , 2}}$ Department of Wildland Resources, Utah State University, Logan, UT 84322, USA \\ JULIE K. YOUNG, ${ }^{3}$ Institute for Wildlife Studies, P.O. Box 1104, Arcata, CA 95518, USA \\ JOHN A. SHIVIK, United States Department of Agriculture, Wildife Services, National Wildlife Research Center, Department of Wildland Resources, \\ Utah State University, Logan, UT 84322, USA
}

\begin{abstract}
Coyotes (Canis latrans) are reported to be less vulnerable to capture in familiar areas of territories, however, most studies do not control for trap density across the territory. We determined if accounting for trap density provided a better explanation of observed capture rates. Based on a sample of 24 captured coyotes ( 6 inside core areas and 18 on peripheries of occupied areas) the best fitting model describing capture location only accounted for trap density and not relative time spent in each region. Our results suggest that coyote capture rates are a function of trap density in an area and not novelty avoidance. Placing traps in core areas of territories can increase the probability of capturing individuals from specific territories to increase the effectiveness of management or research activities. (c) 2011 The Wildlife Society.
\end{abstract}

KEY WORDS Canis latrans, capture location, coyote, familiarity, neophobia, novel object, trappability, wariness.

Understanding movement patterns of resident coyotes (Canis latrans) is important for predation management because residents are most often responsible for livestock depredation (Andelt 1985, Sacks et al. 1999b; Blejwas et al. 2002). If coyotes are more vulnerable to capture in some parts of their territories than others, predation management may be improved with more efficient removal of specific animals (Sacks et al. 1999b; Blejwas et al. 2002).

Presumably, resident coyotes are familiar with the areas of their territory they use regularly and will avoid points of disturbance such as those caused by the placement of traps; it is generally accepted that coyotes are less vulnerable to capture devices within core areas of their territory (Knowlton et al. 1999). Indeed, multiple studies in captivity have found a strong neophobic response of coyotes to novel objects in familiar areas (Windberg 1996, Harris and Knowlton 2001). Although this differential response has been convincingly shown in captivity, it is unclear whether coyotes view traps as novel objects given that traps are generally set to avoid any sign of a disturbance to the environment.

Of those studies looking at spatial bias in coyote captures, most concluded that coyotes were less vulnerable to capture within frequently used areas of their territory (Rucker 1975, Woodruff and Keller 1982, Windberg and Knowlton 1990, 1999a; Gipson and Kamler 2003). In the one study that

Received: 12 May 2010; Accepted: 27 September 2010

${ }^{1}$ E-mail: ryan.wilson@aggiemail.usu.edu

${ }^{2}$ Present Address: The Wilderness Society, 705 Christensen Dr., Anchorage, AK 99501, USA.

${ }^{3}$ Present Address: United States Department of Agriculture, Wildlife Services, National Wildlife Research Center, Department of Wildland Resources, Utah State University, Logan, UT 84322, USA. controlled for differences in trap density between core and peripheral areas, however, the authors found no capture bias (Laundré and Keller 1983). Thus, the question arises: are coyotes truly less vulnerable to capture in core areas because of increased wariness, or is the widely held conclusion of differential coyote capture vulnerability an artifact of methodological biases?

One of the most common methods for analyzing capture data involves contingency tables, which require accurate expectancies for comparison to observed results (e.g., Gipson and Kamler 2003). Not accounting for different trap densities in core and peripheral areas could affect the calculation of expectancies and thus bias results. Therefore, to reliably assess spatial effects in coyote capture probabilities it is essential to account for differences in trap density across an individual's territory.

Our objectives were to determine if coyotes were less vulnerable to capture in their core areas or if the methodological problem of not properly accounting for differences in trap density between core and peripheral areas biased results. Specifically, we used empirical data and Akaike's Information Criterion (AIC) to test if models that account for trap density fit observed core and periphery capture rates better than those that did not.

\section{STUDY AREA}

We conducted our study on the Welder Wildlife Foundation Refuge (approximately 3,150 ha) and a portion of the McFadden Enterprises Ranch (approximately 8,000 ha), which were approximately $10 \mathrm{~km}$ north of Sinton, Texas. The study area was located in a transition zone between the gulf prairies and marshes and south Texas plains, and 
vegetation consisted mainly of mixed grasslands and shrubs (Young et al. 2008).

\section{METHODS}

We captured coyotes with padded foot-hold traps (Victor no. 3 Softcatch, Lititz, PA) during 2003-2005 and 2007-2008 study seasons. We trapped during all months except July, August, and September, when ambient temperatures were too hot to safely capture coyotes. We set traps along roads, trails, fence lines, and power line right-of-ways. Our study site was well-roaded providing wide access for trapping. We often, although not exclusively, placed traps in areas where we observed signs of coyotes (i.e., visual observations, feces, tracks). We used 2 types of trap sets: dirt-holes and baited sets (Dolbeer et al. 1996). We also used a variety of lures at sets (e.g., coyote urine, coyote anal gland, fetid meats, and fruit pastes). Although it is possible that different sets or lures could be perceived differently by coyotes, the diversity of set and lure types we used are representative of most trapping efforts for coyotes and previous studies documenting spatial bias in coyote captures. Also, we did not systematically apply any set or lure type across the study area, so traps had a near-random application of lure or set type. We applied $\geq 1$ type of lure or bait applied to each trap.

We fitted each captured coyote with a very-high frequency radio-collar. We obtained relocations on each individual 4-5 days per week for the first 3 months post-capture (Windberg and Knowlton 1990). We used triangulation and the maximum likelihood estimator in program Locate II (Nams 2006) to estimate animal locations. We used $\geq 3$ bearings collected within $20 \mathrm{~min}$, between $20^{\circ}$ and $160^{\circ}$ of each other, to estimate locations. We chose random start times and animals for telemetry sessions to avoid problems of serial autocorrelation (Fieberg 2007). We collected both diurnal and nocturnal locations for coyotes, as they are active during both time periods (Young et al. 2006).

We estimated the area occupied by individuals with $\geq 30$ locations to ensure that we obtained a sufficient number of relocations to estimate space use patterns (Seaman et al. 1999). We used the fixed kernel method (Worton 1989) with the ad hoc bandwidth selection procedure (see Berger and Gese 2007). We defined a coyote's occupied area as the area encompassed by the $100 \%$ isopleth.

The 95\% isopleth (rather than the 100\%) is frequently used to define a coyote's home range. Excluding 5\% of outlying kernel density estimate intuitively prevented the inclusion of areas not used regularly by the animal (e.g., from infrequent forays) and produced a conservative estimate of home range area. The purpose of our analysis, however, was not to identify the home range, an area an animal traverses in its normal activities (Burt 1943), but rather to identify the area a coyote had a reasonable probability of accessing during a trapping period. We therefore used the $100 \%$ isopeth to include all areas where a coyote could reasonably be attracted to, or interact with, baits and traps. The use of the 100\% isopleth is similar to other capture-location studies, which defined peripheral areas as those $0.5-1.0 \mathrm{~km}$ beyond an estimated territory boundary (e.g., Hibler 1977, Laundré and Keller 1983). Rather than relying on that arbitrary buffer size, however, we used the $100 \%$ isopleth, which is defined statistically and by definition represents the bounds of an area a coyote is likely to be found in.

To define core areas, we analyzed occupied areas for clusters of locations and used Bayesian methods to identify core area isopleths that best fit the observed animal's data set (Wilson et al. 2010). We calculated the percent of time an individual spent in the core area and periphery (i.e., the area between the core area boundary and $100 \%$ isopleth) of their occupied area by determining the relative percent of relocations in each region. We also determined the relative trap density in the periphery and core area for each individual by dividing the number of traps open in each region during the night we captured the coyote by the respective area of each region. We determined latency to capture by determining how many nights a trap was set before it captured a coyote. We could only calculate trap densities within defined core and periphery boundaries, and thus were only used animals that we captured within a defined occupied area in the analyses (i.e., within the $100 \%$ isopleths).

To determine if coyote capture location was related to relative trap density inside the core area, relative use of core area, or both, we parameterized 4 binomial distributions with the expected values for each hypothesis. For the hypothesis that capture location is only related to relative trap density inside the core area, we used the mean relative trap density inside coyote core areas as the mean for the distribution. For the hypothesis that capture location is only related to the relative time spent in the core area, we used the mean proportion of time coyotes spent in their core areas. For the hypothesis that both trap density and time spent in core area explained capture location, we used the average geometric mean of the product of relative trap density and relative time spent in the core area. Lastly, for the null model (i.e., equal capture probability in core and periphery), we used 0.50 as the mean for the distribution. We then obtained the likelihoods of the different parameterizations given the observed capture locations (i.e., core or periphery) for coyotes. We used AIC, adjusted for small sample sizes $\left(\mathrm{AIC}_{\mathrm{c}}\right)$, to determine which of the parameterizations was the best model for the observed data (Burnham and Anderson 1998).

\section{RESULTS}

We captured 27 resident coyotes but were only able to use 24 in analyses; we captured 3 coyotes outside of their occupied area (i.e., outside the $100 \%$ isopleths), including two that had no traps set within their occupied area. We captured a disproportionate majority of coyotes, however, within their occupied area $\left(\chi_{1}^{2}=12.0, P<0.001\right)$.

Coyotes had an average of 6.2 traps $(\mathrm{SD}=3.6)$ open inside their occupied area the night we captured them. All 24 study coyotes had a core area and the mean kernel density isopleth that delineated core areas was $38.1 \%$ (range $10.2-70.0 \%$, $\mathrm{SD}=16.2 \%$ ). Mean percent of time spent (i.e., number of locations) within the core area was $54.4(\mathrm{SD}=16.0)$. Mean size of core areas and peripheries were 0.86 
$(\mathrm{SD}=0.8)$ and $8.7 \mathrm{~km}^{2}(\mathrm{SD}=4.3)$, respectively. Mean trap density (traps $\left./ \mathrm{km}^{2}\right)$ inside core areas and the periphery were $0.9(\mathrm{SD}=1.9)$ and $0.9(\mathrm{SD}=1.0)$, respectively. Relative trap density inside core areas ranged from zero (18 coyotes) to $100 \%$ with a mean relative trap density of 25.3\% $(\mathrm{SD}=40.9)$. Traps that captured coyotes in core areas were open for fewer nights prior to capture $(2.8 \pm 2.8$ days $)$ than were traps that captured coyotes in peripheral areas ( $4.2 \pm 4.2$ days). The geometric mean of the product of the percent of locations within coyotes' core areas and the relative trap density inside the core areas was $21.5 \%$ $(\mathrm{SD}=34.4)$.

We captured 6 coyotes in their respective core areas ( $24 \%$ of captures) and 18 coyotes in the peripheries of their occupied area. Of those coyotes with traps set in their core area, we captured 6 of $7(86 \%)$ coyotes inside their core area; we captured the seventh coyote $31 \mathrm{~m}$ from the estimated core area boundary.

Of the 4 models we tested, the model based on relative trap density as a predictor of capture success was best. The additive model (i.e., traps + time spent in area) did not perform as well but was close to being within $2 \Delta \mathrm{AIC}_{\mathrm{c}}$ (i.e., $\left.\Delta \mathrm{AIC}_{\mathrm{c}}=2.62\right)$ from the best model, although the addition of time did not improve the likelihood (Table 1). The model based on time spent in the core area only provided the worst fit $\left(\Delta \mathrm{AIC}_{\mathrm{c}}=8.36\right)$ even in comparison to the null model $\left(\Delta \mathrm{AIC}_{\mathrm{c}}=4.32\right)$ of equal capturability in core areas and peripheral areas (Table 1).

\section{DISCUSSION}

In our analysis, the top model that accounted for $71 \%$ of AIC weights was the trap density only model. These results indicate that coyote capture vulnerability was primarily a function of the probability of encountering a trap, and not how often they were in a particular area. Although the probability of encountering a trap would likely increase the longer an individual spent in an area, time was not an important factor in our models, likely because similar amounts of time were spent in both core and peripheral areas. It is important to note that we captured in its core area all but one coyote with traps in its core area and the one coyote that we did not capture in the core area we captured close to the core area boundary. Our conclusion is further supported by the observation that latency to capture in the periphery was twice as long as latency to capture in core areas.

Regarding coyotes, our results were similar to those of Laundré and Keller (1983), who also controlled for trap density. Conversely, $66 \%$ of capture location bias studies $(n=12)$ that did not control for trap density found a bias towards capture in peripheral areas (Hibler 1977, Roy and Dorrance 1985, 1993b; Bubela et al. 1998, Harris and Knowlton 2001). The apparent bias in previous studies is likely due to an artifact of not accounting for individual differences in trap density between core and peripheral areas rather than a coyote's familiarity with a core area. Additionally, results of capture location bias studies for other carnivore species show that when trap density is controlled for, a capture bias is not present (1993a; Baker et al. 2001).

Many of the studies that did not control for trap density assumed that traps were evenly distributed across the study regions (e.g., 1999a). Researchers, however, usually do not know a priori where territory or core area boundaries are in the landscape (Laundré and Keller 1983) and because core areas occupy a smaller area than peripheral areas, by chance alone, researchers would tend to place more traps on the periphery than inside the core area. In our study system, peripheral areas were nearly 10 times larger than core areas.

Had we not controlled for trap density and only used the model based on time spent in core and peripheral areas to address the question of capture bias, we would have come to the same conclusion as most other coyote capture bias studies (i.e., disproportionate capture on the periphery). Especially important is controlling for trap density by individual, rather than across the population. As our results show, when viewed across a population, trap densities did not differ between periphery and core areas. When viewed for individuals, however, only 7 of 24 coyotes had traps in the core area. Thus, only $29 \%$ of the population we studied had an opportunity to be captured in the core areas. Previous observations of capture bias are understandable, but it is less parsimonious to attribute the mechanism to coyote neophobic behavior than to trap density.

Our results suggest that coyotes were either not exhibiting an avoidance of novel objects relative to familiar environments, as has been documented in previous studies, or did not view traps as novel objects. We observed greater vulnerability to capture in areas more intensively used by coyotes. Additionally, coyote traps are usually set with lures that do not evoke a neophobic response but rather elicit investigative behavior from coyotes, thus coyotes likely do not view traps as novel objects. As opposed to a novel object, there is no difference in the response of coyotes to novel or familiar odors when presented in familiar and unfamiliar environ-

Table 1. Results of 4 separate binomial models parameterized with different means based on 4 separate hypotheses: 1) capture location is influenced by relative trap density (trap), 2) Capture location is influenced by relative time spent in an area (time), 3) capture location is influenced by both time spent and relative trap density in an area, or 4) equal capture between core and periphery (null). Results are based on capture locations of coyotes $(n=24)$ relative to time spent and trap density in their core area and territory periphery in South Texas from 2003-2005 and 2007-2008. We indicate Akaike's Information Criterion (AIC C $_{c}$, number of parameters $(k)$, Akaike weights $(w)$, chi-square, and $P$-values of chi-square goodness-of-fit tests for each model

\begin{tabular}{lrccccc}
\hline Model & $\mathbf{A I C}_{\mathbf{c}}$ & $\Delta \mathbf{A I C}_{\mathbf{c}}$ & $\boldsymbol{k}$ & $\boldsymbol{w}$ & $\chi^{\mathbf{2}}$ & $\boldsymbol{P}_{\text {-value }}$ \\
\hline Trap & 5.55 & 0 & 1 & 0.714 & 0.17 & 0.683 \\
Trap + time & 8.17 & 2.62 & 2 & 0.193 & 0.00 & 1.000 \\
Null & 9.87 & 4.32 & 0 & 0.082 & 3.77 & 0.052 \\
Time & 13.91 & 8.36 & 1 & 0.011 & 4.57 & 0.033 \\
\hline
\end{tabular}


ments (Windberg 1996). Séquin et al. (2003) used camera traps to capture coyotes and accounted for trap density by evenly distributing traps across territories. Although results of that study suggested coyotes were disproportionately captured more on the periphery than in core areas, cameras might actually act as novel stimuli, unlike traditional traps. Also, unequal distribution of behavior across a territory (Laundré and Keller 1981) could lead to capture biases in camera-trap related studies if coyotes are more active along peripheries than core areas and thus more apt to be photographed.

Because dominant and subordinate coyotes behave differently across a territory (Gese 2001) and possibly differ in their response to novel objects (Séquin et al. 2003), we were curious if any pattern existed with capture location and social status. Although we were unable to definitively determine the social status of each coyote studied due to infrequent observations of interactions between pack members, we used capture (e.g., age at capture, evidence of nursing) and space use information (e.g., frequently traveling with another pack member) to infer social status. Based on these presumed social statuses, we found no evidence for one social status being more or less vulnerable to capture in the core area. In both the core area and the periphery $80 \%$ of captures were alphas, which is interesting given the results of Séquin et al. (2003), who found that alphas were less susceptible to being captured on camera traps. One would also assume greater vulnerability of alpha coyotes to capture on the periphery given their greater levels of territorial defense and patrolling than subordinates (Gese and Ruff 1997, Gese 2001).

Accounting for trap density after animals have been captured and space use patterns estimated is one way to test for capture location bias. But, as we have shown, it is a less-thanideal design because many animals will have no traps placed in their core areas and other factors, such as trap or lure type, are not able to be controlled for between core and peripheral areas. We do not believe that lure or bait type had any effect on our results given our non-systematic allocation of baits and lures to traps as well as our lack of a priori knowledge of whether a trap occurred inside or outside of a coyote's core area. A more powerful design for addressing questions of capture location bias would be to have prior estimates of coyote territory and core area boundaries and then place traps at comparable densities in the 2 regions, which should be easy in study systems where there has been previous coyote research, as coyote territory, and core area boundaries remain stable over long periods of time (Kitchen et al. 2000). This would help provide stronger experimental support for our results.

Finally, considering intensity of space use to be equivalent to familiarity with an area is a potential problem with the conclusion that coyotes avoid traps in core areas due to their familiarity with the areas. Familiarity can be directly manipulated in captive studies (e.g., Windberg 1996) but it would be difficult to manipulate a wild coyote's familiarity within a portion of its occupied area. Just as intensity of use does not necessarily imply quality or importance of habitat infrequent use also does not indicate a lack of familiarity (Van Horne 1983, Garshelis 2000, Powell 2000). Thus, we conclude that factors other than familiarity with an area (e.g., probability of encountering a trap) are more important predictors of capture probability in coyotes and that future studies account for trap densities when assessing capture sight vulnerability.

\section{Management Implications}

If the goal of management efforts is to capture as many coyotes as possible irrespective of pack membership, then our results are probably of little use to trappers. Recent research, however, has shown that only certain coyotes, or packs, are responsible for most livestock depredation (1999b; Blejwas et al. 2002). If managers or researchers want to focus capture efforts on specific individuals or packs (e.g., better distribution of telemetry equipment), then our results can be used to guide trap placement. Identifying habitats that are likely core areas may provide a more efficient means of increasing removal rates of problem individuals or collaring of individuals in desired packs. By placing traps in core areas, specific individuals or packs are most likely to encounter them, thus increasing the specificity of trapping efforts.

\section{Acknowledgments}

We thank the Welder Wildlife Foundation and staff for financial and logistical support and the McFadden Ranch for allowing access to their land. J. du Toit, E. M. Gese, J. A. Bissonette, and J. A. Powell provided valuable comments on an earlier version of the manuscript. This is Welder Contribution number 694. Our research was funded by the United States Department of Agriculte, Wildlife Services, National Wildlife Research Center. Research was approved by Animal Care and Use Committees at Utah State University and the National Wildlife Research Center (QA 1453).

\section{LITERATURE CITED}

Andelt, W. F. 1985. Behavioral ecology of coyotes in south Texas. Wildlife Monographs 94.

Baker, P. J., S. Harris, C. P. J. Robertson, G. Saunders, and P. C. L. White. 2001. Differences in the capture rate of cage-trapped red foxes Vulpes vulpes and an evaluation of rabies control measures in Britain. Journal of Applied Ecology 38:823-835.

Berger, K., and E. M. Gese. 2007. Does interference competition with wolves limit the distribution and abundance of coyotes? Journal of Animal Ecology 76:1075-1085.

Blejwas, K. M., B. N. Sacks, M. M. Jaeger, and D. R. McCullough. 2002. The effectiveness of selective removal of breeding coyotes in reducing sheep predation. Journal of Wildlife Management 66:451-462.

Bubela, T., R. Bartell, and W. Müller. 1998. Factors affecting the trappability of red foxes in Kosciusko National Park. Wildlife Research 25:199208.

Burnham, K. P., and D. R. Anderson. 1998. Model selection and multimodel inference: a practical information-theoretic approach. Springer, New York, New York, USA.

Burt, W. H. 1943. Territoriality and home range concepts as it applies to mammals. Journal of Mammalogy 24:346-352.

Dolbeer, R. A., N. R. Holler, and D. W. Hawthorne. 1996. Identification and control of wildlife damage. Pages 474-506 in T. A., Bookhout, editor. Research and management techniques for wildlife and habitats. The Wildlife Society, Bethesda, Maryland, USA. 
Fieberg, J. 2007. Kernel density estimators of home range: smoothing and the autocorrelation red herring. Ecology 88:1059-1066.

Garshelis, D. L. 2000. Delusions in habitat evaluation: measuring use, selection, and importance. Pages 111-164 in L., Boitani and T. K., Fuller, editors. Research techniques in animal ecology: controversies and consequences. Columbia University Press, Irvington, New York, USA.

Gese, E. M. 2001. Territorial defense by coyotes (Canis latrans) in Yellowstone National Park, Wyoming: who, how, where, when, and why. Canadian Journal of Zoology 79:980-987.

Gese, E. M., and R. L. Ruff. 1997. Scent-marking by coyotes (Canis latrans): the influence of social and ecological factors. Animal Behaviour 54:1155-1166.

Gipson, P. S., and J. F. Kamler. 2003. Capture locations of coyotes, Canis latrans, bobcats, Lynx rufus, and raccoons, Procyon lotor, relative to home range boundaries. Canadian Field Naturalist 117:472-474.

Harris, C. E., and F. F. Knowlton. 2001. Differential responses of coyotes to novel stimuli in familiar and unfamiliar settings. Canadian Journal of Zoology 79:2005-2013.

Hibler, S. J. 1977. Coyote movement patterns with emphasis on home range characteristics. Thesis. Utah State University, Logan, USA.

Kitchen, A. M., E. M. Gese, and E. R. Schauster. 2000. Long-term spatial stability of coyote (Canis latrans) home ranges in southeastern Colorado. Canadian Journal of Zoology 78:458-464.

Knowlton, F. F., E. M. Gese, and M. M. Jaeger. 1999. Coyote depredation control: an interface between biology and management. Journal of Range Management 52:398-412.

Laundré, J. W., and B. L. Keller. 1981. Home range use by coyotes in Idaho. Animal Behaviour 19:449-461.

Laundré, J. W., and B. L. Keller. 1983. Trappability of coyotes relative to home range boundaries. Canadian Journal of Zoology 61:19321934.

Nams, V. O. 2006. Locate III User's Guide. Pacer Computer Software, Tatamagouche, Nova Scotia, Canada.

Powell, R. A. 2000. Animal home ranges and territories and home range estimators. Pages 65-110 in L., Boitani and T. K., Fuller, editors. Research techniques in animal ecology: controversies and consequences. Columbia University Press, Irvington, New York, USA.

Roy, L. D., and M. J. Dorrance. 1985. Coyote movements, habitat use, and vulnerability in central Alberta. Journal of Wildlife Management 49:307313.
Rucker, R. L. 1975. The home range of the coyote (Canis latrans) and its method of calculation. Thesis. Idaho State University, Pocatello, USA.

Sacks, B. N., K. M. Blejwas, and M. M. Jaeger. 1999a. Relative vulnerability of coyotes to removal methods on a northern California ranch. Journal of Wildlife Management 63:939-949.

Sacks, B. N., M. M. Jaeger, J. C. C. Neale, and D. R. McCullough. 19996. Territoriality and breeding status of coyotes relative to sheep predation. Journal of Wildlife Management 63:593-605.

Seaman, D. E., J. J. Millspaugh, B. J. Kernohan, G. C. Brundige, K. J. Raedeke, and R. A. Gitzen. 1999. Effects of sample size on kernel home range estimates. Journal of Wildlife Management 63:739-747.

Séquin, E. S. M., M. Jaeger, P. F. Brussard, and R. M. Barrett. 2003. Wariness of coyotes to camera traps relative to social status and territory boundaries. Canadian Journal of Zoology 81:2015-2025.

Travaini, A., J. Aldama, and M. Delibes. 1993a. Red fox capture locations in relation to home range boundaries. Mammalia 57:448-451.

Travaini, A., F. Palomares, and M. Delibes. 1993b. The effects of capture and recapture on space use in large grey mongooses. South African Journal of Wildlife Research 23:95-97.

Van Horne, B. 1983. Density as a misleading indicator of habitat quality. Journal of Wildlife Management 47:893-901.

Wilson, R. R., M. B. Hooten, B. N. Strobel, and J. A. Shivik. 2010. Accounting for individuals, uncertainty, and multi-scale clustering in core area estimation. Journal of Wildlife Management 74:1343-1352.

Windberg, L. A. 1996. Coyote responses to visual and olfactory stimuli related to familiarity with an area. Canadian Journal of Zoology 74:22482253.

Windberg, L. A., and F. F. Knowlton. 1990. Relative vulnerability of coyotes to some capture procedures. Wildlife Society Bulletin 18:282-290.

Woodruff, R. A., and B. L. Keller. 1982. Dispersal, daily activity, and home range of coyotes in southeastern Idaho. Northwest Science 56:199-207.

Worton, B. J. 1989. Kernel methods for estimating the utilization distribution in home-range studies. Ecology 70:164-168.

Young, J. K., W. F. Andelt, P. A. Terletzky, and J. A. Shivik. 2006. A comparison of coyote ecology after 25 years: 1978 versus 2003. Canadian Journal of Zoology 84:573-582.

Young, J. K., S. N. Glasscock, and J. A. Shivik. 2008. Does spatial structure persist despite resource and population changes? Effects of experimental manipulations on coyotes. Journal of Mammalogy 89:1094-1104.

Associate Editor: Stanley Gehrt. 